\title{
Problem gambling and family violence: Prevalence and patterns in treatment-seekers
}

\author{
N.A. Dowling a,b,c,*, A.C. Jackson ${ }^{\text {b }}$, A. Suomi ${ }^{\text {b,d }}$, T. Lavis ${ }^{\text {e }}$, S.A. Thomas ${ }^{\text {f }}$, J. Patford ${ }^{\text {b }}$, P. Harvey ${ }^{\text {e }}$, M. Battersby ${ }^{\text {e }}$, \\ J. Koziol-McLain ${ }^{g}$, M. Abbott ${ }^{\text {h}}$, M.E. Bellringer ${ }^{\text {h }}$ \\ a School of Psychology, Deakin University, Australia \\ b Problem Gambling Research and Treatment Centre, University of Melbourne, Australia \\ c School of Psychological Sciences, Monash University, Australia \\ ' Centre for Gambling Research, The Australian National University, Australia \\ e Flinders Human Behaviour \&' Health Research Unit, School of Medicine, Flinders University, Australia \\ ${ }^{f}$ Problem Gambling Research and Treatment Centre, Monash University, Australia \\ g Trauma Research Centre, Auckland University of Technology, New Zealand \\ ${ }^{\mathrm{h}}$ Gambling and Addictions Research Centre, Faculty of Health and Environmental Sciences, Auckland University of Technology, New Zealand
}

\section{H I G H L I G H T S}

- The prevalence of any family violence in treatment-seeking gamblers was $33.9 \%$.

- Family violence victimisation prevalence was $27.0 \%$ and perpetration was $22.9 \%$.

- Parents and current or former partners were the most common perpetrators and victims.

- Prevalence was higher in alcohol/drug (84.0\%) and mental health (61.6\%) services.

- The prevalence of problem gambling in the family violence sample was $2.2 \%$.

\section{A R T I C L E I N F O}

Available online 10 July 2014

\section{Keywords:}

Problem gambling

Family violence

Domestic violence

Prevalence

Alcohol

Mental health

\begin{abstract}
A B S T R A C T
The primary aim of this study was to explore the prevalence and patterns of family violence in treatment-seeking problem gamblers. Secondary aims were to identify the prevalence of problem gambling in a family violence victimisation treatment sample and to explore the relationship between problem gambling and family violence in other treatment-seeking samples. Clients from 15 Australian treatment services were systematically screened for problem gambling using the Brief Bio-Social Gambling Screen and for family violence using single victimisation and perpetration items adapted from the Hurt-Insulted-Threatened-Screamed (HITS): gambling services $(n=463)$, family violence services $(n=95)$, alcohol and drug services $(n=47)$, mental health services $(n=51)$, and financial counselling services $(n=48)$. The prevalence of family violence in the gambling sample was $33.9 \%$ ( $11.0 \%$ victimisation only, $6.9 \%$ perpetration only, and $16.0 \%$ both victimisation and perpetration). Female gamblers were significantly more likely to report victimisation only (16.5\% cf. $7.8 \%$ ) and both victimisation and perpetration $(21.2 \%$ cf. $13.0 \%)$ than male gamblers. There were no other demographic differences in family violence prevalence estimates. Gamblers most commonly endorsed their parents as both the perpetrators and victims of family violence, followed by current and former partners. The prevalence of problem gambling in the family violence sample was $2.2 \%$. The alcohol and drug (84.0\%) and mental health (61.6\%) samples reported significantly higher rates of any family violence than the gambling sample, while the financial counselling sample (10.6\%) reported significantly higher rates of problem gambling than the family violence sample. The findings of this study support substantial comorbidity between problem gambling and family violence, although this may be accounted for by a high comorbidity with alcohol and drug use problems and other psychiatric disorders. They highlight the need for routine screening, assessment and management of problem gambling and family violence in a range of services.
\end{abstract}

() 2014 Elsevier Ltd. All rights reserved.

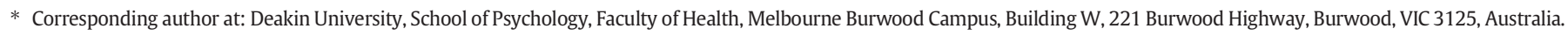
Tel.: +61 39244 5610; fax: +6139244 6858 .

E-mail address: nicki.dowling@deakin.edu.au (N.A. Dowling).
} 


\section{Introduction}

Despite some equivocal findings (Schluter, Bellringer, \& Abbott, 2007; Schluter, Abbott, \& Bellringer, 2008), there is growing evidence that suggests a significant association between problem gambling and family violence. Much of this evidence is derived from studies estimating the prevalence of intimate partner violence (IPV) in problem gambling samples. Despite considerable methodological differences, most of the studies in this area report past year or lifetime IPV victimisation estimates ranging from 60\% to $69 \%$ (Echeburua, Gonzalez-Ortega, De Corral, \& Polo-Lopez, 2011; Kausch, Rugle, \& Rowland, 2006; Korman et al., 2008). In contrast, Raylu and Oei (2009) found that 7\% of 440 treatment-seeking problem gamblers in Australia reported "spouse assault" and 20\% reported "recent experience of family violence and intimidation" in clinical interviews. There is also limited evidence that a significant proportion (56\%) of problem gamblers report past year IPV perpetration (Korman et al., 2008). Findings relating to gender differences in these studies are mixed, with some indicating that women (100\%) are more likely to report lifetime abuse victimisation than men (69\%) (Kausch et al., 2006) and others indicating higher rates of injury perpetration by women (49\%) than men (22\%) (Korman et al., 2008). Echeburua et al. (2011) also found that retirement and "prolonged low" employment were independently related to IPV victimisation in female pathological gamblers.

Other evidence is derived from studies investigating rates of problem gambling in IPV offender samples from batterer intervention programs in the US. These studies have identified rates of problem or pathological gambling ranging from 1 to 24\% (Brasfield, Shorey, Febres, Strong, \& Stuart, 2011; Brasfield et al., 2012; Rothman, Johnson, \& Hemenway, 2006). Although these findings suggest that problem gambling is likely over-represented in samples of IPV offenders, there are currently no prevalence estimates of problem gambling in samples of individuals presenting to treatment services for IPV or family violence victimisation experiences.

Given that alcohol and substance use disorders and psychiatric disorders are highly comorbid with both problem gambling (Dowling et al., in press; Lorains, Cowlishaw, \& Thomas, 2011) and family violence (Krug, Dahlberg, Mercy, Zwi, \& Lorenzo, 2002), there are surprisingly few studies that explore their relationship in other treatmentseeking samples. In a sample of 605 out-of-treatment female substance abusers, Cunningham-Williams, Abdallah, Callahan, and Cottler (2007) found that problem gamblers were more likely to report experiencing parental abuse in their childhoods than nonproblem gamblers.

Although this literature suggests that problem gambling and family violence are highly comorbid, it is difficult to validly compare the rates from the available studies as they are generally limited to IPV, employ US samples, and fail to employ validated instruments. The primary aim of the present study was to explore the prevalence and patterns of family violence in an Australian sample of treatment-seeking problem gamblers. Secondary aims were to identify the prevalence of problem gambling in a family violence victimisation treatment sample and explore the relationship between problem gambling and family violence in other treatment-seeking samples.

\section{Method}

\subsection{Participants and procedure}

In this cross-sectional study, clients from 15 treatment services across 14 Australian agencies were systematically screened for problem gambling and family violence: 8 gambling services (clients seeking treatment for their own gambling problems) $(n=463), 2$ family violence services (clients seeking treatment for family violence victimisation) ( $n=95), 2$ alcohol and drug services $(n=47), 1$ mental health services $(n=51)$, and 2 financial counselling services $(n=48)$. Most services were located in Victoria $(n=11)$, with smaller numbers from Tasmania $(n=3)$ and South Australia $(n=1)$. Participating agencies administered the screening questions to all new clients at intake. Agencies screened for between 1 and 19 months (median $=4.0$ months) and the number of clients screened at each agency ranged from 9 to $199(M=47.2, S D=52.7$, median $=24$ ). Data were collected from August 2009 to March 2012. The resulting sample comprised 704 clients ( 364 men, 320 women, 20 unspecified) ranging in age from 18 to 79 (Table 1). The project was approved by the University of Melbourne Human Research Ethics Committee (0838146) and the Victorian Department of Justice Human Research Ethics Committees (1119644).

\subsection{Measures}

The Brief Bio-Social Gambling Screen (BBGS; Gebauer, LaBrie, \& Shaffer, 2010) was employed to measure past year problem gambling. The BBGS displays high sensitivity (0.96) and high specificity (0.99) in identifying pathological gamblers assessed using the DSM-IV-TR diagnostic criteria in the AUDADIS-IV in a survey of a nationally representative US sample (Gebauer et al., 2010). The BBGS was selected due to its brevity, psychometric properties, and ability to measure problem gambling using few items over a 12-month timeframe. The 4-item Hurt-Insulted-Threaten-Screamed (HITS; Sherin, Sinacore, Li, Zitter, \& Shakil, 1998) was modified into single items measuring past year family violence victimisation (In the past twelve months, has a family member physically hurt you, insulted or talked down to you, threatened you with harm, or screamed or cursed at you?) and perpetration (In the past twelve months, have you physically hurt a family member, insulted or talked down to a family member, threatened a family member with harm, or screamed or cursed at a family member?). Participants were provided with a definition of family members and those endorsing either item were asked to specify their relationship to the relevant immediate or extended family member(s). The original HITS displays high internal consistency $(\alpha=.80$ ) and good concurrent and construct validity (Sherin et al., 1998). The HITS was selected due to its brevity, psychometric properties, and its ability to be converted into a brief screening tool that measures violence extending beyond intimate partners and for perpetration experiences (see Rabin, Jennings, Campbell, \& Bair-Merritt, 2009; Thompson, Basile, Hertz, \& Sitterle, 2006). The items were modified into single items to reduce participant burden during the screening process.

\subsection{Data analysis}

Past year point prevalence estimates were calculated for the proportion of each sample completing each screening instrument. Although only one participant failed to complete the BBGS (0.1\%), there was more missing data for the HITS victimisation (8.4\%) and perpetration (9.0\%) screens. Victimisation data was missing from $43.8 \%$ of the participants from the financial counselling service sample, $22.1 \%$ of the participants from the family violence services, $19.1 \%$ of participants from the alcohol and drug services, $17.7 \%$ of participants from the mental health services, and $1.2 \%$ of participants from the gambling services. Similarly, perpetration data was missing from $43.8 \%$ of the participants from the financial counselling services, $25.3 \%$ of participants from the family violence services, $21.6 \%$ of participants from the mental health services, $21.3 \%$ of participants from the alcohol and drug services, and $1.2 \%$ of participants from the gambling services. More women than expected were missing data for both victimisation $\left(\chi^{2}(2,688)=11.53, p=.004\right)$ and perpetration $\left(\chi^{2}(2,688)=14.70, p=.006\right)$, but there were no other demographic markers for missing data. Demographic differences in family violence estimates in the problem gambling sample were compared using chi-square analyses (with follow-up adjusted standardised residuals [ASRs $>2$ ]) and independent samples $t$-tests. Chi-square analyses were employed to examine any significant group 
Table 1

Summary of demographic characteristics of the study treatment-seeking samples.

\begin{tabular}{|c|c|c|c|c|c|c|}
\hline Demographic characteristic & $\begin{array}{l}\text { Gambling services } \\
(n=463)\end{array}$ & $\begin{array}{l}\text { Family violence services } \\
(n=95)\end{array}$ & $\begin{array}{l}\text { Alcohol and drug services } \\
(n=47)\end{array}$ & $\begin{array}{l}\text { Mental health services } \\
(n=51)\end{array}$ & $\begin{array}{l}\text { Financial counselling } \\
\text { services }(n=48)\end{array}$ & $\begin{array}{l}\text { Total sample } \\
(n=704)\end{array}$ \\
\hline Male (\%) & 63.1 & 35.6 & 40.4 & 26.7 & 22.9 & 52.9 \\
\hline Age (M, SD) & $40.8(12.6)$ & $38.4(11.4)$ & $41.6(12.0)$ & $38.3(11.7)$ & $41.7(14.0)$ & $40.5(12.5)$ \\
\hline Australian born (\%) & 73.3 & 91.8 & 83.0 & 86.7 & 70.8 & 77.0 \\
\hline \multicolumn{7}{|l|}{ Relationship status (\%) } \\
\hline Single, not in a relationship & 46.6 & 25.6 & 55.3 & 28.9 & 60.5 & 44.0 \\
\hline Living with partner & 39.8 & 41.0 & 36.8 & 44.4 & 15.8 & 17.3 \\
\hline Not living with partner & 13.6 & 33.3 & 7.9 & 26.7 & 23.7 & 38.6 \\
\hline \multicolumn{7}{|l|}{ Household status (\%) } \\
\hline Couple with children & 27.1 & 25.6 & 25.6 & 40.0 & 13.5 & 26.9 \\
\hline One parent family & 9.5 & 26.9 & 20.5 & 22.2 & 51.4 & 16.4 \\
\hline Couple with no children & 14.1 & 11.5 & 10.3 & 13.3 & 8.1 & 13.0 \\
\hline Single person household & 24.7 & 16.7 & 41.0 & 13.3 & 18.9 & 23.4 \\
\hline Group/share household & 24.7 & 19.2 & 2.6 & 11.1 & 8.1 & 20.2 \\
\hline
\end{tabular}

differences on family violence and problem gambling between different treatment-seeking samples.

\section{Results}

\subsection{Gambling sample}

The prevalence of family violence in the gambling sample was $27.0 \%$ for victimisation, $22.9 \%$ for perpetration, and $33.9 \%$ for any form of family violence (Table 2 ). Women were significantly more likely to report victimisation than men $\left(\mathrm{RR}=1.8, \chi^{2}(2,463)=15.52, p<.001\right)$. When mutually exclusive family violence groups were explored (Table 2), there was a significant sex difference across the groups $\left(\chi^{2}\right.$ $(6,463)=19.38, p=.007)$, with significantly more women than men reporting victimisation only $(\mathrm{RR}=2.1$ ) and both forms of violence $(\mathrm{RR}=1.6)$. The remaining demographic variables (age, country of birth, relationship status, and household status) were not significantly associated with either victimisation or perpetration. Participants endorsing victimisation identified between 1 and 7 of their family members as perpetrators of that violence (median $=1$ ). They were their parents $(31.9 \%)$, current partners $(21.8 \%)$, former partners (15.1\%), siblings (11.2\%), children (10.2\%), in-laws (5.9\%), and extended family members (4.2\%). Participants endorsing perpetration identified between 1 and 6 of their family members as victims of that violence (median $=1)$. They were their parents $(31.9 \%)$, current partners (27.3\%), former partners (12.1\%), siblings (10.2\%), children $(17.4 \%)$, in-laws (3.3\%), and extended family members (0.9\%).

\subsection{Other treatment-seeking samples}

The prevalence of problem gambling in the family violence services was $2.2 \%$ (Table 2 ). It was not possible to explore the relationships between problem gambling and family violence in the other three services due to the small numbers of screened problem gamblers in these services (Table 2). However, examination of Table 2 reveals that the alcohol and drug sample reported significantly higher rates of family violence victimisation $\left(\mathrm{RR}=2.0, \chi^{2}(1,495)=22.84, p<.001\right)$, perpetration $\left(\mathrm{RR}=2.2, \chi^{2}(1,495)=36.78, p<.001\right)$, and any form of family violence $\left(\mathrm{RR}=2.5, \chi^{2}(1,494)=36.74, p<.001\right)$ than the gambling sample. The mental health sample also reported significantly higher rates of family violence victimisation $\left(\mathrm{RR}=2.3, \chi^{2}(1,499)=23.19, p<.001\right)$ and any form of family violence $\left(\mathrm{RR}=1.8, \chi^{2}(1,496)=12.13, p=\right.$ .004) than the gambling sample. In contrast, the financial counselling sample reported significantly higher rates of problem gambling than the family violence sample $\left(\mathrm{RR}=4.8, \chi^{2}(1,141)=5.05, p=.04\right)$.

\section{Discussion}

The rate of family violence victimisation in the current sample of problem gamblers (27.0\%) was half than those of most previous IPV studies (60-69\%) (Echeburua et al., 2011; Kausch et al., 2006; Korman et al., 2008). It is, however, more consistent with the rates identified in the only available Australian study (Raylu \& Oei, 2009). The rate of family violence perpetration in the current sample of problem gamblers (22.9\%) was also half that identified in previous IPV research (56\%)

Table 2

Prevalence of past year problem gambling and family violence (FV) across treatment services.

\begin{tabular}{|c|c|c|c|c|c|c|c|}
\hline \multirow[t]{2}{*}{ Screen $^{a}$} & \multicolumn{3}{|c|}{ Gambling services (\%; CI 95\%) } & \multirow{2}{*}{$\begin{array}{l}\text { Family violence } \\
\text { services } \\
(\% \text {; CI 95\%) }\end{array}$} & \multirow{2}{*}{$\begin{array}{l}\text { Alcohol \& drug } \\
\text { services } \\
(\% ; \text { CI 95\%) }\end{array}$} & \multirow{2}{*}{$\begin{array}{l}\text { Mental health } \\
\text { services } \\
(\% ; \text { CI 95\%) }\end{array}$} & \multirow{2}{*}{$\begin{array}{l}\text { Financial } \\
\text { counselling } \\
\text { services (\%; CI 95\%) }\end{array}$} \\
\hline & Men & Women & Total & & & & \\
\hline FV victimisation & $20.8(15.6-24.9)$ & $37.6^{\mathrm{d}}(29.3-44.2)$ & $27.0(22.1-30.2)$ & c & $54.1^{\mathrm{e}}(36.2-65.9)$ & $61.9^{\mathrm{e}}(46.6-77.2)$ & $37.0(17.8-56.5)$ \\
\hline FV perpetration & $20.8(15.6-24.9)$ & $26.5(18.6-32.0)$ & $22.9(18.2-25.8)$ & c & $49.3^{\mathrm{e}}(38.4-68.0)$ & $32.5(17.3-45.2)$ & $33.3(14.3-50.2)$ \\
\hline Any form of FV & $28.7(23.0-33.4)$ & $43.0(34.6-49.8)$ & $33.9(29.0-37.6)$ & c & $84.0^{\mathrm{e}}(68.9-95.9)$ & $61.6^{\mathrm{e}}(45.6-77.5)$ & $48.1(28.1-68.3)$ \\
\hline Problem gambling & $\mathrm{b}$ & $\mathrm{b}$ & $\mathrm{b}$ & $2.2(-0.1-5.1)$ & $4.3(-0.2-10.3)$ & $2.0(-0.2-5.9)$ & $10.6^{\mathrm{f}}(1.5-20.2)$ \\
\hline \multicolumn{8}{|l|}{$\begin{array}{l}\text { Mutually exclusive FV } \\
\text { groups }\end{array}$} \\
\hline FV victimisation only & $7.8(4.8-11.1)$ & $16.5^{\mathrm{d}}(11.1-22.6)$ & $11.0(8.3-14.1)$ & c & $16.2(3.8-28.9)$ & $28.2(13.4-43.0)$ & $14.8(4.9-29.1)$ \\
\hline FV perpetration only & $7.8(4.8-11.1)$ & $5.3(1.9-8.9)$ & $6.9(4.8-9.5)$ & c & $18.9(5.7-32.2)$ & $2.6(-2.6-7.8)$ & $11.1(-1.6-23.8)$ \\
\hline $\begin{array}{l}\text { FV victimisation \& } \\
\text { perpetration }\end{array}$ & $13.0(3.6-12.2)$ & $21.2^{\mathrm{d}}(13.8-26.1)$ & $16.0(11.7-18.2)$ & c & $48.9(31.8-65.5)$ & $30.8(15.6-45.9)$ & $22.2(5.5-39.0)$ \\
\hline
\end{tabular}

a Base sample sizes vary due to missing data (see data analysis section).

b Gambling programs did not administer the BBGS.

c Family violence programs did not administer the HITS.

d Significant gender difference in problem gambling sample $(p<.05)$.

e Significant difference with family violence estimates in comparison to problem gambling sample $(p<.05)$.

${ }^{\mathrm{f}}$ Significant difference between problem gambling estimate in comparison to family violence sample $(p<.05)$. 
(Korman et al., 2008). While the rates may reflect lower prevalence in Australia relative to other jurisdictions, they may also reflect the use of the adapted HITS items that measured multiple forms of violence in single items and did not measure some forms of violence, such as sexual violence. Because the complexity of family violence presentations is poorly captured by current screening instruments that tend to comprise too many items to be usefully employed in screening or focus on intimate partner victimisation experiences (see Rabin et al., 2009; Thompson et al., 2006), future research may benefit from the further development and validation of brief screens for violence extending beyond intimate partners and for perpetration experiences. Finally, this study is the first to examine the prevalence of problem gambling in individuals seeking assistance related to family violence victimisation (2.2\%).

Although the failure to employ a community-based control group precludes definitive conclusions about these estimates relative to the general population, the past year family violence victimisation rate in gambling treatment services (27.0\%) was 25 times higher than the past year physical and/or sexual IPV victimisation rate (1.1\%), and 7 times higher than the past year emotional IPV victimisation rate (3.8\%), in the Australian population (Australian Bureau of Statistics, 2013). Similarly, the rate of past year problem gambling in family violence victimisation treatment services (2.2\%) was 2 to 4 times higher than in the Australian population (0.5-1.0\%) (Jackson, Wynne, Dowling, Tomnay, \& Thomas, 2010). Although these comparisons are not entirely valid as different definitions and measures of problem gambling and family violence were employed, they suggest that further investigation of the relationship between problem gambling and family violence is warranted.

The highest proportion of the gambling sample reported both family violence victimisation and perpetration, raising the possibility of reciprocal violence occurring in problem gambling families (Suomi et al., 2013). Consistent with Kausch et al. (2006), women were 2.1 times more likely to report victimisation only and 1.6 times more likely to report both victimisation and perpetration than men. Although this study provides an acontextual acts-based measurement of family violence (Taft, Hegarty, \& Flood, 2001), the finding that nearly half of female problem gamblers report some form of family violence suggest that this group of service users should be specifically targeted for screening, assessment and management. Finally, the parents, partners, and former partners of the gamblers were most commonly endorsed as both perpetrators and victims of family violence. Evidence of high rates of family violence victimisation and perpetration by the parents of problem gamblers has also been noted in a study investigating the prevalence of family violence in a small sample of the family members of problem gamblers (Suomi et al., 2013). Moreover, there are findings to suggest that parents of problem gamblers report equivalent financial, emotional, social life, employment, and physical health impacts to partners (Dowling, Rodda, Lubman, \& Jackson, 2014). Although the precise nature of the relationship between problem gambling and family violence remains unknown, preliminary findings have suggested that problem gambling precedes both victimisation and perpetration of family violence (Suomi et al., 2013). This implies that gambling-related stressors, such as the loss of family financial resources, abdication of family role responsibilities, mistrust, and poor communication may result in chronic family stress, domestic conflict, and the perpetration of violence by parents and partners (Echeburua et al., 2011; Korman et al., 2008) and that gambling losses and other problems may result in the manifestation of stress, anger, and financial crisis within the home and lead to the perpetration of violence by the problem gambler against parents and partners (Afifi, Brownridge, MacMillan, \& Sareen, 2010; Korman et al., 2008; Muelleman, DenOtter, Wadman, Tran, \& Anderson, 2002). Regardless of the nature of the relationship, the findings that parents are involved highlights the importance of studying violence that extends into problem gambling families beyond intimate partners and children (Jackson, 2003; Ulman \& Straus, 2003).

The findings of this study underscore the need that other services, such alcohol and drug services, mental health services, and financial counselling services, should develop screening, referral and management protocols for problem gambling and family violence. The rate of problem gambling in the financial counselling sample was 4.8 times higher than that in the family violence sample while the rates of family violence in the alcohol and drug and mental health samples were 1.8 to 2.5 times higher than those in the problem gambling sample. The high rates of family violence in clients attending alcohol and drug services and mental health services are not unexpected, given there is substantial evidence that family violence is highly comorbid with alcohol and drug use problems and mental health issues (Krug et al., 2002). However, problem gambling is also highly comorbid with alcohol and drug use problems and psychiatric comorbidities (Dowling et al., in press; Lorains et al., 2011). It is therefore possible that the rates of family violence observed in the problem gambling treatment sample may reflect an association of family violence with alcohol and substance use problems or psychiatric comorbidity, rather than any specific association with gambling problems. There is evidence that alcohol and substance use problems and psychiatric comorbidity exacerbate the relationship between problem gambling and family violence (Afifi et al., 2010; Brasfield et al., 2011, 2012; Goldstein, Walton, Cunningham, Resko, \& Duan, 2009; Kausch et al., 2006; Leiseur \& Rothschild, 1989; Muelleman et al., 2002). However, there are some conflicting findings with some studies failing to report these associations (Echeburua et al., 2011; Korman et al., 2008; Schluter, Abbott, \& Bellringer, 2008). Moreover, approximately two-thirds of the family members of problem gamblers report there is an association between problem gambling and family violence (Muelleman et al., 2002; Suomi et al., 2013). The findings of this study therefore highlight the need for further research investigating the role of alcohol and substance use problems and mental health problems in the relationship between problem gambling and family violence.

The findings of this study support substantial comorbidity between problem gambling and family violence, although this may be accounted for by a high comorbidity with alcohol and drug use problems and other psychiatric disorders. Further research, including prospective studies, are needed to advance our understanding of the relationships between problem gambling, family violence, and these psychiatric comorbidities. Although the achieved rates of screening in these samples are superior to average rates of clinician-administered screening for alcohol, drug, and mental health problems (Edlund, Unutzer, \& Wells, 2004; Groves et al., 2010), it is unlikely that agencies screened every client and there was a considerable amount of missing family violence data. This indicates future replication with researcher-administered screening is warranted. The findings of this study can, however, inform specific approaches to prevention and intervention efforts and responsible gambling and violence prevention policies. They highlight the need for routine screening, assessment and management of family violence in problem gambling services and gambling problems in family violence services.

\section{Role of funding sources}

This research was funded by the Australian Research Council (Linkage Grant LP 0989331) with the Office for Problem Gambling, South Australia and Drummond Street Services, Victoria as industry partners; and the Problem Gambling Research and Treatment Centre at the University of Melbourne.

\section{Contributors}

AJ, ND and ST designed the study; ND wrote the first draft of the manuscript; AS, TL, and JP were involved in data collection; and AS project managed and led the data analysis All authors contributed to and approved the final manuscript and all meet the NH \& MRC guidelines for authorship.

\section{Conflict of interest}

The authors declare that they have no competing interests. 


\section{Acknowledgements}

This research was funded by the Australian Research Council (Linkage Grant LP 0989331) with the Office for Problem Gambling, South Australia and Drummond Street Services, Victoria as industry partners; and the Problem Gambling Research and Treatment Centre at the University of Melbourne. The research team would like to acknowledge the effort of the participating agencies in Victoria, South Australia and Tasmania, and the clients who participated in the study.

\section{References}

Afifi, T. O., Brownridge, D. A., MacMillan, H., \& Sareen, J. (2010). The relationship of gambling to intimate partner violence and child maltreatment in a nationally representative sample. Journal of Psychiatric Research, 44(5), 331-337.

Australian Bureau of Statistics (2013). Personal safety, Australia, 2012. Available: http://www.abs.gov.au/ausstats

Brasfield, H., Febres, J., Shorey, R., Strong, D., Ninnemann, A., Elmquist, J., et al. (2012). Male batterers' alcohol use and gambling behavior. Journal of Gambling Studies, 28, 77-88.

Brasfield, H., Shorey, R., Febres, J., Strong, D., \& Stuart, G. L. (2011). Hazardous gambling among women court-mandated to batterer intervention programs. American Journal on Addictions, 20(2), 176-177.

Cunningham-Williams, R. M., Abdallah, A. B., Callahan, C., \& Cottler, L. (2007). Problem gambling and violence among community-recruited female substance abusers. Psychology of Addictive Behaviors, 21(2), 239-243.

Dowling, N. A., Cowlishaw, S., Jackson, A.C., Merkouris, S. S., Francis, K. L., \& Christensen, D. R. (2014). The prevalence of comorbid personality disorders in treatment-seeking problem gamblers: A systematic review and meta-analysis. Journal of Personality Disorders (in press).

Dowling, N. A., Rodda, S. N., Lubman, D. I., \& Jackson, A.C. (2014). The impacts of problem gambling on concerned significant others accessing web-based counselling. Addictive Behaviors, 39(8), 1253-1257.

Echeburua, E., Gonzalez-Ortega, I., De Corral, P., \& Polo-Lopez, R. (2011). Clinical gende differences among adult pathological gamblers seeking treatment. Journal of Gambling Studies, 27(2), 215-227.

Edlund, M. J., Unutzer, J., \& Wells, K. B. (2004). Clinician screening and treatment of alcohol, drug, and mental problems in primary care: Results from healthcare for communities. Medical Care, 42(2), 1158-1166.

Gebauer, L., LaBrie, R., \& Shaffer, H. J. (2010). Optimizing DSM-IV-TR classification accuracy: A brief biosocial screen for detecting current gambling disorders among gamblers in the general household population. Canadian Journal of Psychiatry, 55(2), 82.

Goldstein, A. L., Walton, M.A., Cunningham, R. M., Resko, S. M., \& Duan, L. (2009) Correlates of gambling among youth in an inner-city emergency department. Psychology of Addictive Behaviors, 23(1), 113-121.

Groves, P., Pick, S., Davis, P., Cloudesley, R., Cooke, R., Forsythe, M., et al. (2010). Routine alcohol screening and brief interventions in general hospital in-patient wards: Acceptability and barriers. Drugs: Education, Prevention, and Policy, 17(1), 55-71.

Jackson, D. (2003). Broadening constructions of family violence: Mothers' perspectives of aggression from their children. Child and Family Social Work, 8(4), 321-329.
Jackson, A.C., Wynne, H., Dowling, N. A., Tomnay, J. E., \& Thomas, S. A. (2010). Using the CPGI to determine problem gambling prevalence in Australia: Measurement issues. International Journal of Mental Health and Addiction, 8(4), 570-582.

Kausch, O., Rugle, L., \& Rowland, D. Y. (2006). Lifetime histories of trauma among pathological gamblers. The American Journal on Addictions, 15(1), 35-43.

Korman, L. M., Collins, J., Dutton, D., Dhayananthan, B., Littman-Sharp, N., \& Skinner, W. (2008). Problem gambling and intimate partner violence. Journal of Gambling Studies, 24(1), 13-23.

Krug, E. G., Dahlberg, L. L., Mercy, J. A., Zwi, A. B., \& Lorenzo, R. (Eds.). (2002). World report on violence and health. Geneva: World Health Organisation.

Leiseur, H. R., \& Rothschild, J. (1989). Children of Gamblers Anonymous members. Journal of Gambling Behavior, 5(4), 269-281.

Lorains, F. K., Cowlishaw, S., \& Thomas, S. A. (2011). Prevalence of comorbid disorders in problem and pathological gambling: Systematic review and meta-analysis of population surveys. Addiction, 106(3), 490-498.

Muelleman, R. L., DenOtter, T., Wadman, M. C., Tran, T. P., \& Anderson, J. (2002). Problem gambling in the partner of the emergency department patient as a risk factor for intimate partner violence. Journal of Emergency Medicine, 23(3), 307-312.

Rabin, R. F., Jennings, J. M., Campbell, J. C., \& Bair-Merritt, M. H. (2009). Intimate partner violence screening tools. American Journal of Preventive Medicine, 36(5), 439-445.

Raylu, N., \& Oei, T. S. (2009). Factors associated with the severity of gambling problems in a community gambling treatment agency. International Journal of Mental Health and Addiction, 7(1), 124-137.

Rothman, E. F., Johnson, R. M., \& Hemenway, D. (2006). Gun possession among Massachusetts batterer intervention program enrollees. Evaluation Review, 30(3), 283-295.

Schluter, P. J., Abbott, M. W., \& Bellringer, M. E. (2008). Problem gambling related to intimate partner violence: Findings from the Pacific Islands Families study. International Gambling Studies, 8(1), 49-61.

Schluter, P., Bellringer, M. \& Abbott, M. (2007). Maternal gambling associated with families' food, shelter, and safety needs: Findings from the Pacific Islands Families study. Journal of Gambling Issues, 19, 87-90.

Sherin, K. M., Sinacore, J. M., Li, X. Q., Zitter, R. E., \& Shakil, A. (1998). HITS: A short domestic violence screening tool for use in a family practice setting. Family Medicine, 30(7), 508-512.

Suomi, A., Jackson, A.C., Dowling, N. A., Lavis, T., Patford, J., Thomas, S. A., et al. (2013). Problem gambling and family violence: Family member reports of prevalence, family impacts and family coping. Asian Journal of Gambling Issues and Public Health, 3(1), 1-15.

Taft, A., Hegarty, K., \& Flood, M. (2001). Are men and women equally violent to intimate partners? Australian and New Zealand Journal of Public Health, 25(6), 498-500.

Thompson, M. P., Basile, K. C., Hertz, M. F., \& Sitterle, D. (2006). Measuring intimate partner violence victimization and perpetration: A compendium of assessment tools. Atlanta (GA): Centers for Disease Control and Prevention, National Center for Injury Prevention and Control.

Ulman, A., \& Straus, M.A. (2003). Violence by children against mothers in relation to violence between parents and corporal punishment by parents. Journal of Comparative Family Studies, 34(1), 41-60. 